\title{
HISTÓRIA DA REVISTA DO SERVIÇO PÚBLICO A PARTIR DA ANÁLISE DOS SEUS EDITORIAIS
}

\section{Tania Mezzomo Keinert \\ José Carlos Vaz}

\section{Introdução}

-

objetivo dieste artigo é apro-

fundar o entendimento da trajetória da Revista do Serviço Público, trazendo novos elementos para análise do papel da publicação. Faz parte de projeto de pesquisa mais amplo, voltado à reconstituição do campo conhecimento em administração pública no Brasil. São preocupaçôes da pesquisa a natureza, a disciplinaridade, os paradigmas, a evoluçāo e as tendências da administração pública no Brasil.

A pesquisa adotou como objeto empírico a produção brasileira cm administração pública. Inicialmente analisou-se aquela publicada na Revista de Administração Pública (RAP) no período entre 1967 e $1992 .{ }^{1}$ valiaçāo da trajetória da RSP através da análise de conteúdo de seus editoriais no periodo 1937-1989. O artigo visa complementar o anterior - uma análise quantitativa trazendo novos elementos, desta vez qualitativos, para a análise do papel da publicação na evoluçâo do pensamento administrativo brasileiro. Receberam destaque os temas prioritariamente abordados pelos editoriais da Revista: DASP, Reforma Administrativa, Recursos Lumanos e a própria publicação. As conclusōes desta etapa da pesquisa acompanham, de maneira geral, aquelas anteriormente apresentadas, refletindo a tran sformaçâo dos estudos sobre o Estado brasileiro, de uma abordagem técnico-burocrática para uma tentativa de implantação de políticas públicas.

Na fase atual está sendo realizada a análise da Revista do Serviço Público, desde sua fundaçāo, em 1937, até o ano de 1989, quando sua publicação foi interrompida. ${ }^{2}$

- Ver MEZZOMO KEINERT, T. M. \& LAPORTA C.B. "A RAP e a Evolução do Campo de Administraçáo Pública no Brasil (1967-1992)”. Revista de Administraçāo Pública, (28) 1:5-17, janciro-março de 1994, RJ, FGV.

2 - A Revista foi lançada em novembro de 1937, como órgão do Consellıo Federal do Serviço Público Civil (CFSPC). Em 1938, com a criação do Departamento Administrativo do Serviço Público (DASP), em substitu ição ao CFSPC, passou à condição de órgão oficial do departamento. No período 1981-1989 foi publicada pela FUNCEP - Fundação Centro de Formaça do Servidor Público. Na fase atual, iniciada neste ano (1994), sua publicaçào está sob responsabilidade da Escola Nacional de Administraçāo Pública (ENAP). 
m artigo anterior, foi apresentada uma reconstituição histórica da trajetória da Revista, com base na produção nela publicada, destacando as características por ela assumidas em cada periodo, além do papel cumprido na evolução do campo de conhecimento $\mathrm{cm}$ administraçāo. Esta análise tomou como base a classificação dos artigos publicados em termos de focus e locus - instrumental té́rico utilizado e objeto empirico analisado, respectivamente. ${ }^{3}$

Este artigo tem caráter complementar ao primeiro. Foi eleita como metodologia para sua elaboração o estudo de uma das principais fontes primárias disponiveis - os editorais da Revista - onde se apresenta o posicionamento oficial daqueles que dirigem a publicaçāo. Foi realizada, portanto, uma análise de conteúdo, colocando em evidência as falas dos editores.

Face ao papel central desempenhado pela Revista na evoluçáo do campo de conhecimento em Adiministração Pública no Brasil, o artigo se detém nos principais temas abordados pela Revista, conforme análise expressa no artigo anterior.
A estruturação do artigo tomou como base esses temas na forma das opin ióes emitidas pela Revista - através de seus editoriais - sobre si própria, sobre o DASP (Departamento Administrativo do Serviço Público), sobre a Reforma Administrativa e sobre Recursos Humanos. Sua seleção deveu-se à relevância $\mathrm{em}$ relaçāo ao objeto da pesquisa $e$ à forte presença nos editoriais (e artigos) da Revista do Serviço Público. Ao longo do periodo 1937-1989, esses temas são constantemente abordados. $O$ DASP, pelo seu papel na estruturaçāo do Estado brasileiro pós-1930 e por ser o responsável pela publicação na maior parte do tempo, recebe da Revista uma grande atenção. A reforma administrativa (ou os vários processos de reforma administrativa parcialmente realizados) e recursos humanos são dois temas que apresentam uma ligação muito sólida com o DASP, principal instrumento do Estado para promover a reforma administrativa e modernizar a administração de recursos humanos no setor público.

As conclusōes desta etapa da pesquisa, aqui apresentadas, contribuem para o seu objetivo geral, fornecendo novos indicativos para o estudo do papel da

- MEZZOMO KEINERT, T. M. \& VAZ, J. C. "A Revista do Serviço Público no Pensamento Administrativo Brasileiro (1937-1989)”, Revisıa do Serviço Público janciro-julho de 1994, Brasília, ENAP. 
Revista do Serviço Público na evoluçāo do campo de conhecimento cm administração pública.

\section{A Revisia do Serviço Público fala de si mesma}

Revista do Serviço Público surge comprometida com o objetivo do governo Vargas de implantaçāo de um novo modelo de Fstado, com capacidade de cumprir as novas tarefas a cle destinadas no processo de industrialização do país. Esse compromisso será intensamente assinalado pelos editores da Revista, principalmente ao longo dos primeiros periodos de sua existência (1937-1945 c 19461964). ${ }^{4}$

Em seu primeiro editorial, em 1937, a Revista assinala "o aparecimento de uma técnica de serviço público" e se apresenta com a missão de contribuir para a formação do funcionalismo público $\mathrm{cm}$ função do aumento da eficiência do trabalho realizado:

"Pela leitura regular desta Revista, todos os servidores do Estado poderão $[\ldots]$ desenvolver $[\ldots]$ a mentalidade adequada a habilitálos nāo só ao exercício mais eficiente de suas funçōes, como mesmo a sugerir inovaçōes úteis ao aperfeiçoamento do serviço público" (RSP, ano I, vol. I, $\mathrm{n}^{\circ} 1$, novembro de 1937 , o grifo não consta do original).

Os primeiros editoriais basciam-se, com frecuüência, nos princípios da administração científica, referindose a autores clássicos como Willoughby, White e Pfffiner. ${ }^{5}$

Assim, afirmam que a administração pública deve ser exercida como técnica científica, proclamando sua neutralidade.

Iim abril de 1946, no entanto, o editorial comunica uma mudança de orientação da Revista. Ocorre uma tentativa - timida - de incorporar a discussão política na Revista. O antigo e "admirável clima neutral" vem a ser substituído pela pretensâo em ser

"um espelho vivo do nosso Executivo, refletindo diretrizes, técnicas c aspiraçōes, oferecendo-se lisamente ao impacto

\footnotetext{
- Foi adotada aqui a mesma periodizaçáo utilizada para a análise dos dados obtidos na primeira fase da pesquisa: 1937-1945. 1946-1964, 1965-1979 c 1980-1989. Para uma just ificativa desta periodização, ver MEZZOMO KELNERT \& VAZ, op. cit.

s - Ver, por exemplo, RSP, ano VI, vol. II, n³, junho de 1943.
} 
parlamentar, facilitando assim o ansiado controle bicameral, que poderá cercear-lhe arroubos, mas the dividirá as responsabilidades. [...] Antes éramos o órgão do funcionalismo público, vivendo exclusivamente dele e para ele. Daqui além, graças à recomposição de nossos quadros governamentais, procuraremos alargar $o$ antigo âmbito da Revista do Serviço Público, dirigindo-nos conscientemente para três grupos distintos: uma clientela geral, o público; uma clientela especifica, o funcionalismo; e uma clientela especial, o Parlamento." (RSP, ano IX, vol.II, $n^{\circ} 1$, abril de 1946).

Já há um grupo razoavelmente extenso a quem interessa a reflexāo sobre temas da administração pública. A Revista procura dirigir-se também a esse grupo, sem abandonar sua tarefa de formação dos servidores públicos. Adaptando-se à redemocratizaçāo após o Estado Novo, estabelece um discurso baseado em idéias democráticas. Com isso, abre espaço para divergências em substituição à unanimidade anteriormente preponderante.

Paralelamente, verifica-se um processo de sofisticação de seus temas: vai se reduzindo a preocupação com atividades de organização admin istrativa básica (padronização de materiais, recursos humanos, datilografia) e ganham espaço artigos mais aprofundados, já se iniciando uma produção teórica nacional cm administração pública. ${ }^{6}$

Nesse mesmo momento ocorre uma mudança da estrutura da Revista, com o acréscimo de seçôes destinadas a textos de autores estrangeiros, Ad ministração Local; História Administrativa do Brasil; Orçamento; Organização (na verdade, Organizaçāo \& Métodos); Administraçāo de Pessoal; Seleçāo c Aperfeiçoamento de Pessoal; Direito e Jurisprudência. A Revista acolhe, então, uma produção nacional emergente em administração pública, em grande parte representada por jovens autores ligados ao serviço público, alguns dos quais recebendo formaçāo nos Estados Unidos.

6 - A título de exemplo para essa comparação, ver BERLINK, E. L. "A Padronizaçāo dos Papéis de Expediente". (RSP, ano 1 , vol. $I$, n' 1 , novernbro de 1937) e FURTADO, Celso M., "Teoria do Departamento de Administração Geral" (RSP, ano IX, vol. U, $\mathrm{n}^{\circ} 2$, maio de 1946).

? Por cxcmplo, Celso Furıado, Benedicto Silva, Beatriz Warlich, Guerreiro Ramos, entre outros. 
ssa crescente sofisticação da produção vai levar a Revista, em 1963, a realizar uma transformação na sua linha editorial. Se antes as páginas da Revista estavam

\section{"abertas a todos os funcionários públicos e a todos os estudiosos, sem exigência outra que não a da serenidade dos trabalhos destinados à impressão" (RSP, ano XXI, vol.79, $\mathrm{n}^{\circ} 1$, abril de 1958. O grifo não consta do original)}

e a Revista tinha circulação mensal, ela passa a ter circulação trimestral e amplia o nivel de cxigência dos artigos publicados. A Revista comunica a mudança através de um editorial sugestivamente intitulado "Menos Volume, Mais Qualidade":

"Nosso objetivo é fazer da RSp um órgāo [...] reconhecido e acatado como tal por diretores, assessores, técnicos de administração, enfim, por toda a classe dos que participam no complexo processo de formular politicas, selecionar objetivos e dirigir a administração dos negócios públicos" (RSP, ano XXIV, vol. $91, \mathrm{n}^{\circ} 1,2,3$, abril a junho de 1963).
As alterações na estrutura ou na apresentaçāo da Revista são sempre exibidas pelos seus editores, nos dois primeiros periodos, como resultado de uma constante busca de uma modernidade cujo parâmetro é a experiência $\mathrm{e}$ a produção científica estrangeira, notadamente dos Estados Unidos. Uma mudança de formato é, portanto

"uma adequação às
exigências da vida
modema" (RSP, ano XVA,
vol. $66, n^{\circ} 1$, janeiro de
1955).

Novas formas de classificação, apresentação ou de numeração são mostradas como

"o mais modemo método" (idem).

ou como acompanhando

"a evolução dos recursos técnicos de que se têm servido as melhores publicações estrangeiras" (RSP, ano XXI, vol.79, n' 1 , abril de 1958).

A idéia de se constituir num instrumento de ligação com o moderno continua presente nos editoriais do terceiro período de vida da Revista do Serviço Público, que se apresenta: 
"reafirmando suas virtualidades como fator de modernização institucional e aprimoramento dos recursos humanos engajados na epopéia quotidiana do desenvolvimento nacional." (RSP, vol. $108, \mathrm{n}^{\circ}$ 3 , setembro a dezembro de 1973).

Entretanto, a Revista já não dispõe do mesmo prestígio de vinte ou trinta anos atrás. Em 1974 sua publicação é interrompida. $O$ editorial do último número desse periodo, paradoxalmente intitulado "Novas Dimensōes e Perspectivas para a Revista do Serviço Público", apesar de mencionado no índice, nāo está presente na Revista. Im seu lugar, foi colocada a seguinte nota, sem nenhum outro comentário:

"O editorial foi retirado por nāo refletir a orientaçāo da direção geral do DASP." (RSP, vol. 109, no 2 , abril a junho de 1974).

Quando a Revista foi relançada, em 1981, passou a ser publicada pela FUNCEP, ógão para o qual grande parte das funções remanescentes do DASP foram transferidas, especialmente formação de servidores. ${ }^{8}$

A Revista, em seu quarto periodo (1981-1989), volta-se novamente para o público interno - o funcionalismo. Entretanto, cabe ressaltar que o funcionalismo público nos anos 80 é bastante diferente daquele dos anos 30 , para quem a Revista inicialmente se dirigiu. Já existe a figura do "executivo de Estado" - o administrador público profissional - e um numeroso corpo de técnicos atua nas administraçōes direta $\mathrm{c}$ indireta. Como a fase de estruturaçāo administrativa do Estado em seus aspectos básicos já estava concluída há muito tempo", as necessidades de informação e formaçāo do funcionalismo assumem um novo caráter. A Revista percebe e reflete essa diferença:

"A exigência merilocrática reclama, na atualidade, que - servidor público descortine horizontes científicos e humanísticos cada vez mais complexos e inter-relacionados, a fim de

- Para uma análise mais aprofundada da trajetória do DASP, ver MARCELINO, G. F. Evoduçāo do Estado e reforma administrativa, Brasília, ALAPSEDAP, 1987; ANDRADE, A. Contribuiçāo a história ndministraltua do Brasil. Rio de Janeiro, José Olímpio Ed., 1950; BITTENCOURT, C. DASP: como um imperativo democrático e técnico, Brasilia, Serv. de Documentaçào do DASP, 1966; SIEGEL, G. B. The vicissitudes of government and reform in Brazil: a study of the DASP, Ann Arbor, Xerox Univ. Microfilms, 1975 (tese-Univ. Pittsburgh, 1964); Brasil. Departamento Administrativo do Serviço Público, Rio de Janciro, 1930, 1944.

9 - Ver MEZZOMO KEINERT \& VAZ, 1994, op. cit. 
permanecer familiarizado com as principais inovações de nosso tempo." (RSP, ano 38, vol. 109, $\mathrm{n}^{\circ}$ 4 , outubro a dezembro de 1981, o grifo não consta do original).

Ao contrário dos periodos anteriores, a formação de scrvidores é vista de forma mais ampla, e não somente limitada aos aspectos técnicos em estrito senso. Entretanto, não deixa de lado, nessa nova fase, o servidor que não faz parte da elite intelectual, pois:

"A Revista do Serviço Público ressurge inspirada pela consciência da crescente necessidade de manter a funçāo pública em contato regular com análises objetivas, em linguagem acessivel, dos grandes temas políticoadministrativos de nossa época." (idem, o grifo nāo consta do original).

Ao longo deste quarto periodo, a Revista continua sempre voltada ao funcionalismo. Ao mesmo tempo que procura apresentar contribuiçōes de autores de qualificaçāo intelectual reconhecida, preocupa-se em ser

"rica em ilustraçōes c didática no conteúdo" (RSP, novembro e dezembro de 1985).

A Revista do Serviço Público, ao falar de si própria, procura transmitir, sempre, a idéia de uma publicação voltada à divulgação de produçāo de ponta em administração pública. $\grave{A}$ medida que ocorre um desenvolvimento do campo de conhecimento, a Revista procura acompanhá-lo, sempre se considerando parte importante dessa trajetória. Procura fazê-lo mantendo-se voltada à missão de formação do funcionalismo público, característica constantc dos órgãos aos quais esteve ligada.

\section{O DASP na Revisia do Serviço Público}

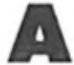

Revista do Serviço Público procura sempre destacar o DASP como modernizador da administração pública em todos os aspectos, legitimando sua existência e suas atribuiçōes junto ao público leitor. Como publicação oficial do órgāo (até passar a ser editada pela FUNCEP, cm 1981), principalmente no periodo 1937-1945 e no periodo 1946-1964 cla se empenha cm divulgar suas atividades $c$ opiniōes. Serve, também, de instrumento nos embates políticos por ele travados com segmentos da sociedade e do governo. 
Defendendo a criação do DASP, em 1938, a Revista - que o precedeu em um ano - $O$ apresenta como peça fundamental para a construção do "arcabouço político duradouro" para o país proposto pelo Estado Novo. Afirmando que "governar é admin istrar", defende que

"o sucessu de qualquer programa governamental se acha largamente condicionado à eficácia da ação administrativa". (RSP, ano I, vol. III, $\mathrm{n}^{\circ} 2$, agosto $\mathrm{de}$ 1938).

\section{A mudança de mentalidades}

Além das atividades voltadas diretamente à reorganização $\mathrm{e}$ modernizaçāo administrativa do Estado, a Revista aponta uma outra missão do órgão, voltada à promoção de mudanças de caráter cultural. Assim, podemos dizer que o Estado Novo utiliza-se da Revista e do DASP para operar uma mudança não só de técnicas e da organização do Estado, mas também de mentalidade, ao ressaltar

"a poderosa influência psicológica exercida pela obra do DASP, tanto entre os servidores do Estado [...] como entre o público em geral [...]. Aí está, também, a influência exercida pelo DASP nas administraçōes regionais, muitas delas já se pautando pelas normas de administração geral adotadas no serviço federal, por serem, de fato, as recomendadas pela doutrina $e$ pela prática." (RSP, ano $V$, vol. IV, $\mathrm{n}^{\circ} 3$, dezembro de 1942).

A Revista do Serviço Público, dessa forma, contribui para as atividades de propaganda do governo ditatorial de Getúlio Vargas. f: importantc, inclusive, observar a constante referência às figuras dos presidentes da república e do DASP. Entretanto, mesmo depois do final do Estado Novo essa tendencia prossegue, principalmente no segundo período $(1946-1964){ }^{10}$

\section{- DASP como centro de Poder}

Com o crescimento dos poderes do DASP, a Revista afirma, referindo-se a ele, que seu
"crescimento não se processou pela absorção de novos encargos mas por uma extensa penetração de

10 - Nota: a título de exemplo vide RSP, ano V, vol. II, n 2 , maio de 1943 , para o primeiro periodo, e RSP, ano XXII. vol. 84, n' 3, setembro de 1959, para o período seguinte. 
suas at ividades no campo da política a que se propôs clar contcúdo real." (RSP, ano VI, vol. I, $n^{\circ} 1$, de 19.13).

I:m janciro de 1946, com a retirada das funçōes exccutivas do DASP, transformando-o em um "óngāo de estudo e orientação da administração do serviço civil", o editorial se posiciona de forma cautclosa, dizcndo, inclusive, que a Revista nāo tem como atribuição estabelecer julgamentos ou comparaçōes entre a fase do listado Novo e a fase de rede. mocratizaçào posterior a 19:45. O texto afirma que a Revista do Scrviço Público

"não cabe o exame dos principios implicados e dos falos ocorridos nas duas fascs da vida nacional" (RSP, ano $\mathrm{LX}$, vol. $I, n^{\circ} 1$, janciro (lc 19:16).

Isssa mudança de atribuiçōes e de estrutura do DASP respondeu afirmativamentc a críticas anteriores da imprensa c do público. 'Tais criticas atingiam

"atos c modos de açāo do DASP" (idem).

A Revista também nâo analisa cssas criticas. Dì, referindo-sc ao órgão, que reconhecemos virtudes, também sabemos ver os scus erros e defeitos" (ibidem).

O editorial apresenta como argumento justificativo para a reestruturação, a opinião de que, antes da queda de Getúlio Vargas,

"a tendência do DASP era crescer, absorvendo funçōes, menos por culpa sua que em rayão do estado de coisas no país" (ibidem).

() editorial procura associar o crescimento do poder do DASP nāo a disputas politicas intemas ao Isstado, da qual o órgão houvesse tomado parte, mas à dinâmica natural do governo do listado Novo, diferente do novo regime, instaurado com a queda de Getúlio Vargas.

Ao longo do texto, a linguagem impessoal vai sendo substituida por uma identificação entre Revista e DASP. O editorial assume a primeira pessoa do plural para contmpor-se especialmente a uma acusação: a de ser o DASP um órgão anti-democrático:

"Se é verdade que tín hamos mais atribuições que as de um órgão da natureza do nosso em um regime essencialmente democrálico, não nos cabe,

"agora como antes, se lhe 
todavia, a pecha de antidemocráticos, primeiro porque em países universalmente reconhecidos como liberais, há organismos administrativos com principios e estrutura parecidos com os nossos; segundo, porque o con tacto com os servidores do DASP fará com que qualquer pessoa verifique, entre nós, a existência de partidarios de todas as idéias, o que, evidentemente, contradiz os principios postos $\mathrm{cm}$ ação nos países totalitaristas" (ibidem).

A Revista admite que a retirada de atribuiçōes do DASP provocou celcuma. O DASP, além das funçōes de pessoal, ficou como órgāo consultivo para os sistemas de orçamento, organização c construção de edifícios públicos.

Havia, entretanto, interessados no desaparecimento do órgão. $\Lambda$ Revista procura justificar a mudança sem, desta vez, recorrer a angumentos teóricos. Apresenta apenas o exemplo da Civil Service Commision dos IUA, que considera com um escopo de atuação similar ao do DASP.

Apesar da mudança de govemo, a Revista não assume uma crítica ostensiva ao regime ou à gestāo do DASP anteriores. O corpo de técnicos do DASP se mantinha estável c exibia uma relativa autonomia. As criticas assumem uma forma discreta, sempre reconhecendo valores e procurando transmitir as responsabilidades do DASP para o govemo e a situação política. Isto pode ser visto, por exemplo, no editorial de fevereiro de 1946 intitulado "O DASP na Democracia":

"A complexidade e a variedade das atribuiçōes do DASP, bem como a circunstância de ter sido criado e de ter adquirido pleno desenvolvimento num regime politico de supercentralização administrativa, determinaram, insensivelmente, a progressiva ampliação de sua esfera de ação. Ile chegou, por isso, a ultrapassar sua discreta condição de órgão de consulta do Presidente, ao ponto de constituir o paradoxo de uma cauto. limitação da ditadura. Jamais um órgāo do govemo exerceu critica tão severa, franca c ostensiva em tomo dos problemas c projetos governamentais. Fatalmente, cssa conduta, que denunciava e prevenia erros e excessos do poder, teria de atrair simpatias c descontentamentos que, 
invariavelmente, surgem quando interesses personalistas são fiscalizados ou contrariados" (RSP, ano IX, vol. I, $n^{\circ} 2$, de 1946 , o grifo não consta (lo original).

A Revista afirma, portanto, que a atuação do DASP, no Isstado Novo, criava conflitos porque materializava o confronto entre o poder do conhecimento e da técnica c o poder polílico. $O$ DASP, scgundo a Revista, utilizava - poder da técnica de que dispunha para realizar a "autolimitação" do primeiro governo de Getúlio Vargas. O DASP é apresentado como um órgão que defende a supremacia c neutralidade da técnica e que, por esse caráter, pode guiar-se unicamente pelos interesses da nação.

Lsse mesmo editorial volta a defender mudanças no DASP, face às modificaçōes na conjuntura político-institucional do país. A Revista posiciona-se a favor de que o órgão tenha suas funçōes de intervenção reduzidas e que, como resultado, passe a trabalhar mais como "um laboratório silencioso":

"Mesmo assim, talvez não esteja isento de instituir-se cm novo paradoxo, tão hon roso quanto o anterior, de pretender, em pleno regime de livre opiniāo, opor a supremacia lécnica ao aventurismo improvisador e anárquico. (...) os serviços administrativos (...) precisam acobertar-se de todas as inferências estranhas às normas da técnica moderna e da ciência da administração." (idem, o grifo não consta do original.)

Algum tempo mais tarde, em janciro de 1947, a Revista reivindica o retomo ao DASP clas suas antigas funçōes de controle sobre o sistema de material da União, alegando que, com a retirada dessa atribuição c sua passagem para o Departamento Federal de Materiais, órgão antes controlado passou a ser também o controlador do sistema. O DASP quer voltar a ser responsável por "amparar os orgãos de material, proporcionando-lhes uma legislação especial, cuja finalidade precípua será manter os controles diretos $\mathrm{c}$ indiretos especiais, que visem desembaraçar o sistema da legislação ordinária, sempre tardia para codos os novos problemas que o cotidiano da administração suscila".

Para justificar sua reivindicação, a Revista se bascia nas tcorias sobre controle, já vendo a administração como um sistema composto de subsistemas. interessante 
observar que a Revista, desta vez, deixa de ser cuidadosa como de hábito e critica a situação instituida (pelo Governo Judiciário que antecedeu o governo Dutra).

A defesa do DASP na Revista toma sempre ares de defesa do modelo de Estado promotor do desenvolvimento através da intervenção direta na economia, cm contraposição às posiçōes liberais:

"Efetivamente, as criticas (...) se explicam, em sua quase totalidade, como a reação incvitável dos últimos abencerragens dos velhos conceitos e tipos de Estado adstritos à nāointervençāo na esfera econômica e à simples manutençāo da ordem pública. São os retardatários que ainda não compreenderam as exigências da organização técnica do Estado Moderno cm um mundo cada ve\% mais dominado pelo determinismo da divisão do trabalho, $[$... $]$ e da inevitável profissionalização do serviço público. [...] 'l'odavia, as críticas formuladas com mais insistência, contra essa entidade visceralmente democrática e de caráter essencialmente técnico (...) o que se pretende, de plano, sob os mais variados pretextos, é mutilar, ou, quiçá, suprimir a instituição para o assalto aos cargos públicos, o reestabcle- cimento do 'pistolāo'e das percentagens por compras, a climinação dos concursos, provas honestas ou quaisquer barreiras que porventura se levantem em defesa dos legitimos interesses da Nação" (RSP, julho de 19亿8).

Lfetivamente, no campo da moralização do acesso à carreira pública e à profissionalização do funcionalismo, a con tribuição do DASP não pode ser minimizada. $O$ sucesso de suas incursóes nesse campo serviu como elemento justificador do poder que assumiu, especialmente no Estado Novo e nos primeiros anos subseqüentes.

\section{- DASP como órgão de excelência técnica}

O DASP é sempre apresentado como óngāo de excelên cia, que, de certa forma, antecipa a obra a que se propõe pelos scus próprios mélodos de trabalho. Como exemplo, pode-se citar o seu rclarório anual de 1939, publicado pela Revista na edição de maio de 1940. Referindo-se à estrutura do 
relatório, o editorial o apresenta como:

"documento informativo da situaçāo administrativa do país. /.../ não se limita a focalizar as attvidades exercidas pelo Departamento (...) Elaborado de um ponto de vista inteiramente diferente, encerra uma utilíssima análise da administração" (RSP, ano III, vol. II, no. 2, maio/1940, p. 3, o grifo não consta do original).

İ possivel identificar, nos editoriais, a prática de defender pontos de vista valendo-se de argumentos fundamentados $\mathrm{em}$ teorizaçōes, utilizando-se como fundo as idéias que circulavam na produçāo cien tífica cm administração pública no exterior. Assim, para defender a instituição dos relatórios anuais para todos os órgãos da administração pública, no editorial da edição de setembro do ano seguinte, novamente a Revista comenta um relatório anual do DASP, considerando-o modelo. Primeiramente classifica o serviço público, in cluindo-o no rol das grandes organizaçôes, para depois tcorizar a respeito:

"Nas grandes organizaçôes, de que o Serviço Público é um dos exemplos mais frisantes, torna-se impraticável a verificação direta dos resultados do trabalho. Quanto maior a rede de serviços, mais importante o papel que o relatório desempenha, porque é através dele que se toma contato com as diferentes unidades." (RSP, ano IV, vol III, no. 3, setembro de 1941).

\section{A importância do DASP}

O DASP é visto como elemento fundamental na transformação do Estado brasileiro em todos os períodos de sua existência. Seu trabalho é considerado pilar do campo de conhecimento $\mathrm{cm}$ admin istração pública no lBrasil.

Nos seus momentos iniciais, a Revista preocupa-se cm diferenciar a Administração Pública da Ciência Jurídica, procurando mostrar que se trata da criaçâo de um novo campo, vinculado à Ciência Administrativa. ${ }^{11}$

A Revista fala da importância do DASP salientando, ainda, a abrangência de sua obra através de diferentes aspectos. Assim, sua visāo da obra do DASP lembra, ao longo dos anos que cle criou no serviço público civil 
"uma nova men talidade, no sentido de se organizarem as repartiçōes sobre bases racionais, de acordo com principios já experimentados cm outros paises, com succsso, c ajustados às peculiaridades da nossa adiminisıraçāo." (RSP, ano VII, vol. III, $\mathrm{n}^{\prime \prime} 2$, agosto de 194.1).

lím vírios anos, a importãncia do DASP c destacada em editoriais comemorativos do aniversário de criação do óngảo:

"Com a criaçāo, em 30 de jutho de 1938, do Departamento Adminis- trativo do Serviço Público, a Administração Federal superou uma $c$ iniciou outra clapa de sua evolução, deixando para tris, resolutamente, a fase do empirismo absoluto c abrindo sua estrutura c seu funcionamento aos prin- cípios da organização científica." (RSP, ano VIII, vol. III, $n^{\circ} 2$, agosto de 19.(5).

Há outras manifestaçōes da importância do DASP:

“(..) milhares de publicaçōes avulsas e a ediçāo desta Revista constituem acervo e veículo de doutrinas e prálicas que impressionam positivamente qualquer observador honesio no seu exame." (RSP, ano XVII, vol. IU, $\mathrm{n}^{\circ}$ 3, setembro de 19.45).

I:m julho de 1960, um editorial da Revisla do Serviço Público coloca a importância do DASP para a adminisırıçāo, federal, estadual c municipal e mesmo privada:

"Na luta da racionalização
administrativa no Brasil,
tem sido este Departamento
o pequeno David, lutando
contra o Golias da cor-
rupção c do nepotismo".
l... "Hoje é o DASP, sem
nenhuma dúvida, o mais
completo órgāo de
administração geral exis-
tente no mundo, tendo
realizado com exito a mais
vasta revolução raciona-
lizadora". (RSP, ano XXII,
vol. 88 , no 1, julho de
1960)"

$\Lambda$ importância dada ao DASP lambém se liga à valorizaçāo da experiência estrangeira: assim como os editoriais da Revista constantementc citam autores dos IUA C vírios artigos tracluziclos são publicados, também destina clogios à política de enviar

12 - Para outros cxemplos, ver tambem RSP, ano XXII, vol. 84, $0^{\circ} 2$, agosto de 1959 RSP. ano XXX vol. 99, $n^{\circ} 3$ e 4, jullo a dezembro de 1967 , RSP, vol. $105, n^{\circ} 2$, maio a agosto de 1970; RSP, vol. 108, n० 1. janciro a abril de 1973. 
anualmente turmas de funcionários ao estrangeiro, para fins de "aperfeiçoamento" dando "muito sensatamente"

"preferência decidida, se nāo exclusiva, aos Estados Unidos da América" (RSP, ano VIII, vol. I, $n^{\circ} 1$, janciro de 19:5).

A Revista defende o papel de constituição de uma clite de técnicos de admin istração através desse instrumento:

"o comércio leal de idéias entre as elites concorre mais para o entendimento harmonioso dos povos do que a simples manutenção de relaçōes diplomáticas e comerciais" (iclem, o grifo não consta do original).

A Revista entende que o DASP de fato teve papel fundamental na formação da clite intelectual pretendida:

"As boas sementes plantadas pelo DASP não serão desperdiçadas: elevar a administração pública à categoria de uma ciência; generalizar as técnicas de investigação cientifica; |... lo DASP él um dos raros núcleos de estudos administrativos existentes no país, onde se forma uma plêiade de técnicos e profissionais necessários ao Estado." (RSP, ano XI, vol. U, n $n^{\circ} 3$ c 4 , julho e agosto de 1948).

Por ocasiāo do $21^{\circ}$ an iversário do DASP, no editorial referente a setembro de 1959, a Revista do Serviço Público noticia o discurso do presidente Juscelino Kubitschek de Oliveira, onde este clogia as atividades do DASP. O editorial é construído de forma a enfatizar a importância do órgão. Percebe-se o intuito de defendêlo dos ataques costumeiros:

"Nāo será extinguindo-o, ou mutilando suas atribuiçōes básicas e multiformes, que se atenderá aos reclamos de ordem e eficiência no serviço público." O DASP é apresentado como "patrimônio do país e do povo". 'Tem uma "missão reformadora" frente ao Estado brasileiro (RSP, ano $\mathrm{XXUI}$, vol. 84, no 3 , setembro de 1959).

\section{DASP e RSP: um parentesco multo próximo}

Com breves momentos de relativa autonomia, a Revista se comporta como óngāo do DASP. No primeiro periodo defende as idéias do departamento; no segundo e terceiro, precisa defendê-lo em sua luta pela sobrevivência e pela 
manutenção de sua importância dentro do Fstado.

A Revista apresenta o DASP como grande demiurgo de um novo Estado e da admin ist ração pública no Brasil. Na veiculação dessas posiçōes, em alguns momentos, DASP e Revista do Serviço Público se confundem e são apresentados como um todo homogêneo. Mesmo quando o DASP já está enfracyuccido, esta inter-relação permanece. Para aprofundá-la, o que não se encontra no escopo deste artigo, a alternativa metodológica mais recomendável é pesquisar a composição dos grupos que, ao longo da vida da publicaçāo, tiveram papel decisório sobre seu conteúdo. Mais precisamente, os diretores da publicação e do DASP c aqueles que desempenharam papéis de orientação e aconsclhamento formal ou nào - quanto a sua linha editorial.

\section{Reforma administrativa}

H importância c atcnção destinada pela Revista às realizaçōes do DASP e o desiaque que oferece à temática da reforma admin ist rativa.

No primeiro periodo da vida da Revista, vários editoriais c artigos abordam o tema. 'I'rala-se da grande preocupação do governo do listado Novo, da missão do DASP c também da publicação. Falando da "reforma administrativa brasileira", a Revista a apresenta como um

"movimento irreprimivel [... no sentido de reconstruir a aparelhagem do serviço público" (RSP, ano IV, vol. IV, $\mathrm{n}^{\circ} 2$, novembro de 1911).

A Revista (xupa-se, ainda, da defesa c divulgaçāo das mediclas tomadas pelo govemo federal, especialmente no campo do funcionalismo público. É caso da lei ${ }^{\circ} 281$, de 1936, conhecida como leei de Reajustamento de Quadros, que alterou a classificação e vencimentos do funcionalismo da União. A Revista refere-se a cla como

"símbolo da reforma administrativa brasilcira" (idem).

Mesmo após o fim do listado Novo, a Revista busca obter legitimidade para a reforma administrativa realizada sob a orientação do CFSPC e do DASP. Tray o exemplo da experiência francesa, onde encontra problemas e soluçōes semelhanıes ao caso brasileiro em um

"paralelismo impressionante $[\ldots]$ entre as providências tomadas, em 
1945, pelo governo francês, para assegurar a eficiência de sua máquina administrativa, e a reforma do Serviço Civil brasileiro." (RSP, ano VIII, vol. IV, no 3 , dezembro de 1945). ${ }^{13}$

As posições assumidas pela Revista quanto à reforma administrativa estão correlacionadas com as opiniōes emitidas a respeito do DASP. Na verdade, no período 1937-1945 a reforma administrativa é inclissociada do órgão.

A partir do segundo periodo (1946-1964), a Revista fala em reforma administrativa quase sem se referir ao DASP, exceto com relação ao passado. No entanto, a Revista vê a reforma administrativa como um movimento inevitável, como ilustra o episódio da Campanha de Simplificação Burocrática, de 1956, promovida pelo governo federal, que criou uma comissão que se propunha desburocratizar o "organismo" estatal, e da qual o DASP participava na Secretaria Ixxecutiva. Apresentando a
Campanha, a Revista afirma:

"Do ponto de vista fenomenológico, a Campanha surge aos olhos dos estudiosos como $\mathrm{m}$ mevento inevitável e previsível. É a marcha natural de um organismo [o Lstado] que se viu forçado a crescer, $[\ldots]$ e que $[\ldots]$ multiplicou os quadros de seus servidores c ampliou a área de sua influência direta" (RSP, ano XIX, vol. $72, n^{\circ} 1$, julho de 1956). ${ }^{14}$

Mas o movimento vigoroso dos anos 30 perdeu sua força e logo a Revista admitiria que não havia mais uma reforma administrativa em curso. No início da década de 60 , a Revista faz uma crítica contundente à situação do arcabouço administrativo:
"lodas as modificaçōes significativas introduzidas na máquina administrativa [...] ocorreram de 1931 a 1939. $[\ldots]$ O sistema administrativo do Governo

13 - A Revista toma como principal referência internacional a administraçào pública dos EUA e, em menor grau de importáncia, da Inglaterra e da França.

14 - Nos três primeiros periodos de sua existência, a Revista toma como referência fundamental a Escola Clássica e a de Administraçào Científica. Entretanto, seus cditoriais em nenhum momento trazem a preocupaçäo de manifestar um posicionamento claro quanto a filiaçào a escolas do pensamento administrativo. Preocupaçōes e termos das escolas comportamentalistas surgem em diversos editoriais. Neste editorial, por exernplo, a Revista ut iliza a linguagen das escolas comportamentalistas de Administraçào (Relaçöes Humbnas e Behaviorista). $O$ aprofundamento dessa questão dependeria de uma classificação individualizada dos cditoriais em funçào do focrus adotado. preocupação exclu ida do escopo deste artigo. que parte de una precoupaçào de análise ternática. 
da União é obsolcto historicamente, inadequado c canhestro qualitativamente." (RSP, ano XXV. vol. $95, n^{\circ} 2$, de 1962).

Mais adiante, a Revista proclama a necessidade da reforma administrativa, apesar de compreender que o tema já perdeu força na agenda de políticas públicas para outras "reformas". Não obstante, luta para mantê-lo em cvidência, ainda que sabendo do pouco interesse que despertava. Em um editorial de 1962, a Revista pede, em um tom de certa forma ressentido, a inclusão da reforma administrativa entre as "demais reformas":

"Que venha a reforma administrativa, juntamentc com as demais reformas que parecem contar com patronos mais prestigiosos $\mathrm{e}$ mais dinâmicos que os daquela. $[\ldots]$ Que seja adequada em envergadura à nossa extensão continental; realista $\mathrm{cm}$ instrumentos, objetivos, $[\ldots]$ estribada no acervo moderno de conhecimentos e experiências da administraçāo científica" (RSP, ano XXV, vol.95, $n^{\circ} 2$, abril a junho de 1962).

Ou, no mesmo ano, falando sobre os "problemas prementes com que o Brasil se vê a braços no momento", destaca que

"[...] falta, porém, acrescentar um: a reforma administrativa. 1 preciso fazĉtla com urgência" (RSP, ano XXV, vol. $94, \mathrm{n}^{\circ} 4$, outubro a dezembro de 1962).

Ao final do segundo periodo, em 1963, o anteprojeto da Lei Orgânica do Sistema Administrativo Federal conferia ao DASP a atribuição de conduzir a reforma administrativa. A Revista opina favoravelmente, mas admite que há resistências, contra as quais procura interceder:

"O que parece não ser de consensus omnium é a entrega, ao DASP,da atribuiçāo de dinamizar a Reforma. $|\ldots|$ O que resta, portanto, ć esperar que [...] seja garantido ao DASP o estímulo e apoio de todos para que a reforma administrativa seja mantida no caminho do sucesso" (RSP, ano XXVI, vol $95, n^{\circ} 4$, outubro a dezembro de 1963).

Com o golpe militar de 1964, o tema da reforma administrativa assume nova importância, embora o mesmo não ocorra com o DASP:

"O Govemo advindo com a Revolução de 31 de março 
de 1964 compreendeu, aliás, o grau de urgência que a reforma administrativa requer, ao organizar uma comissão de alto nivel" (RSP, ano XXVTW, vol. 97, $\mathrm{n}^{\circ}$ 4 , de 1965).

O DASP, que já perdia sua importância no governo, se vê amcaçado de extinçāo:

"Um dos traços característicos da reforma programada, talvez o mais expressivo, é o da extinção de um órgão central de administraçāo geral". (idem)

A Revista apresenta a mudança sem questioná-la, admitindo-a plenamente. A antiga defesa do DASP parece esgotada. A mudança empreendida pelo golpe de 1964 é mais radical que a ocorrida em outros momentos de troca de governo até então: a Revista alinha-se às posições do governo sem timidez e sem mencionar qualquer forma de oposiçāo externa.

Ėntretanto, o DASP nāo é extinto nessa cocasião. İm 1966, novamente a Revista empreende uma defesa da reforma administrativa sob o controle do DASP:

"Por isso, não parece inteligível a notícia de que a atividade de Organização, e sua superintendência na aplicação do plano, seria retirada do DASP. No Brasil, no momento, só há uma instituição capaz, adcquada e com a indispensável experiência para o exercício das atividades de [...] reforma da administração pública: o DASP" (RSP, ano XXXX, vol. $98, n^{\circ} 3$, julho a setembro de 1966).

A reforma administrativa, entretanto, nāo fica sob o controle do DASP, e sim é assumida pela Secretaria de Planejamento da Presidência. A Revista critica de forma velada o encaminhamento:
"Sendo o DASP o mais expressivo e antigo repositório de competência técnica em matéria de administração pública no Brasil, parece não the falecer autoridade para oferecer um conselbo construtivo e ponderado sobre tão importantc problema" (RSP, ano XXXX, vol. $98, n^{\circ} 4$, outubro a dezembro de 1966, o grifo nāo consta do original).

A autoridade para este "conselho construtivo c ponderado" baseiase na competência técnica atribuida ao DASP. No entender da Revista há necessidade de um 
"amplo debate do projeto de reforma por parte da opinicio técnica do país, e preparaçāo psicológica, para obter aceitação, motivação e cooperaçāo," porque "não se concebe que pessoa ou grupo isolado elabore um plano de reonganizaçāo $[\ldots]$ sem uma ampla e extensa consulta à opinião técnicoespecializada do país" (idem, o grifo nāo consta do original).

Com a designaçāo do Ministério do Planejamento e Coordenação Geral para a condução da reforma administrativa, a Revista e o DASP se subordinam a um papel de colaboraçāo com o novo óngāo:

"deverá a Revista do Serviço Público fazer convergir para aquela colaboração com o Ministério do Plancjamento e Coordenação Geral seu interesse preponderante. [...] A reforma administrativa, juntamente com as experiências semelhantes em andamento nos países mais desenvolvidos, constituirāo os grandes temas prioritários da Revista do Scrviço Público" (RSP, ano XXXI, vol. $100, \mathrm{n}^{\circ} 1$ e 2 , janciro a junho de 1968).

Apesar dessa afirmação, o tema deixa de ser destaque nos editoriais da Revista no restante do terceiro periodo (1965-1979).

Com o fim do governo militar, a temática da reforma administrativa volta à tona, como uma das açōes necessá rias à redemocratização. A Revista é editada pela FUNCEP . que assumira sua publicação em 1981 - subordinada ao Ministério da Administraçāo, responsável pela reforma administrativa. 'Transcreve palavras do min istro da Administraçāo, Aluízio Alves, afirmando que a Revista do Serviço Público

"espelhará, em última análise, o corpo vivo da reforma. [...] a Revista será o órgão de divulgaçāo mais nobre da reforma administrativa do Governo Federal." (RSP, novembro e dezembro de 1985, p.5).

De fato, vários artigos são publicados sobre o tema, mas a Revista sofre muitas interrupções e mudanças no periodo, que impedem que desempenhe adequadamente este papel.

\section{Uma preocupação constante}

A reforma administrativa mantémse, ao longo dos quatro periodos estudados, como uma preocupação constante da Revista do Serviço Público. A publicação ocupa-se da defesa de sua 
oportunidade e viabilidade, tanto nos momentos em que as iniciativas oficiais encontram resistência, quan to nas situaçōes em que o governo não manifesta maior interesse pelo tema. Este fato é explicado pela própria gênese da Revista, cm meio a um profundo movimento de Reforma Administrativa. O fato de ser ediıada pelo DASP garantiu, nos primeiros três periodos estudados (1937-1945, 1946-1964, 19651980), a presença, na Revista, de um corpo de profissionais formados a partir desse movimento e de suas idćias. No quarto periodo (1981-1989), a Revista está ligada ao órgão responsável pela reforma administrativa (neste caso, o Ministćrio da $\Lambda \mathrm{dmin}$ istração), o que garante que o tema continue sendo de central importância para a publicação.

Os recursos humanos na Revista do Serviço Público

Devido à sua penetração junto ao funcionalismo público federal, os editoriais da Revista cumpriram, muitas vezes, tarefas de divulgação e defesa de decisóes governamentais na área de administração de pessoal.

Nos quatro periodos estudados, as questōes referentes a recursos humanos são constantemente abordadas. Há um número expressivo de editoriais sobre o tema. Ao longo do tempo, podemos perceber, porém, uma mudança do foco central de interesse dentro da temática, passando das questões referentes à administraçāo de pessoal para uma cada vez maior valorização da formação de pessoal.

Quando do surgimen to da Revista do Serviço Público, a administração de pessoal era prioridade do governo federal. No ano anterior, 1936, havia sido promulgada a lei $n^{\circ} 284$, de reajustamento do funcionalismo, que a Revista sempre apresentou como

"o início de uma fase de renovação na vida do serviço público federal" (RSP, ano I, $n^{\circ} 2$, janciro de 1938 ).

A tarefa colocada ao DASP, que editava a Revista, passava necessariamente pela

"profissionalização rigorosa
do funcionalismo" enten-
dida como uma "condição
imprescindivel à cxistência
de uma administração
pública a altura dos
tremendos problemas
defrontados pelas socieda-
des contemporâncas" (RSP,
ano I, no 3, fevereiro de
1938).

"profissionalização rigorosa do funcionalismo" entendida como uma "condição imprescindível à existência de uma administraçāo pública à altura dos tremendos problemas defrontados pelas sociedades contemporâncas" (RSP, 1938) 


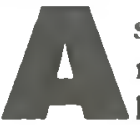

$s$ medidas de regulamentação do funcionalismo sempre receberam grande destaque da Revista, preocupada com a profissionalivação e com a eficiência. Assim, quando da criação do listatu to dos Funcionários Públicos Civis da União, a Revista dedica um editorial ao tema, defendendo sua adoção e classificando seus críticos, como

"os tardígrados do rançoso liberalismo de fachada" (RSP, ano I, vol. IV , $n^{\circ} 3$, dezembro de 1938).

No segundo periodo, a idéia de profissionalização do funcionalismo persiste, sendo apresentada em diversos editoriais, normalmente tratando de temas como classificação de cargos, estatuto do funcional ismo e outras alteraçōes na legislação. ${ }^{13}$

A Revista, nos seus anos iniciais, defende um pesado investimento do Estado no "aperfeiçoamento e especializaçāo de funcionários". lim editorial de 1939, defende a importância dessa atribu içāo do recém-criado DASP, apresentando o exemplo do trabalho realizado no Ministério da Agricultura, no qual a forma de atuação do DASP recebcu críticas, rebatidas pela Revista:
"Ao con trário do que supōe tanta gente mal informada, nāo houve, por parte do mesmo, nesse caso, nada que se assemelhasse a uma imposiçāo" (RSP, ano II, vol. UU, n³, setembro de 1939).

Fortemente ligada às experiências estrangeiras, a Revista, pródiga em traduçōes e citaçōes, defendeu com veemência tanto a vinda de técnicos estrangeiros como o envio de técnicos brasileiros para formaçāo no exterior. Já aponta nessas práticas o germe de um corpo de profissionais brasileiros qualificados. Iim seu editorial de março de 19:40, a Revista aponta a possibilidade:

\section{"A vinda de técnicos cstrangeiros seria uma esplêndida oportunidade para desenvolver cursos [...] que poxliam mais tarde ser continuados com o nosso próprio elemento" (RSP, ano IUI, vol. I, no 3 , março de 19:(0).}

A carreira de técnico de administração é saudada, quando do seu aparecimento, em 1940. lintretanto, anos mais tarde, cm 1956, a Revista é obrigada a admitir, face ao desinteresse pela carreira nos órgãos públicos, apontando que só o DASP e o

13 - Ver editoriais da RSP de fevereiro de 1951, janciro de 1952, outubro de 195.1. entre outros. 
Ministério da Justiça a adotaram, que

"foi uma idéia feliz que parece não ter medrado" (RSP, ano XVIU, vol. 71, $\mathrm{n}^{\circ}$ 1, abril de 1956).

Prevendo um insatisfatório resultado do concurso que seria realizado, a Revista é pessimista:

"retrogradamos sensivelmente." A Revista afirma que não "alimentam esperanças de uma brilhante seleção os que têm conhecimento [...] das condiçōes de funcionamento da administração geral." (idem)

Nessa discussão, a Revista indica um fator que considera responsável pelo desinteresse dos técnicos em administração pela administração pública:

"o 'Técnico de Administração $[\ldots] t \mathrm{~cm}$, presentemente, na indústria ou no comércio, maiores e melhores oportunidades do que no governo federal" (iclem).

O entusiasmo anterior no campo dos recursos humanos se esvai, face à cristalização, ao longo dos anos, das principais características da administração de pessoal do governo federal. No terceiro e quarto periodos, as abordagens prescritivas de administração de pessoal desaparecem. A Revista opta por apenas divulgar as in iciativas governamentais no campo da legislação de pessoal e as implicaçōes das açōes de reforma administrativa para o funcionalismo.

\section{Os recursos humanos como} elemento central

O lema recursos humanos é central à vida da Revista, em função mesmo da atuação do DASP nesse campo, marcada por uma atuação sistemática e coerente no sentido da profissionalização do funcionalismo público. A Revista sempre apoiou e divulgou as ações empreendidas nessa direção, como a implan tação do sistema de mérito, do ingresso na carreira por concurso público, treinamento e formação técnica de pessoal.

Entretanto, à medida que o İstado brasileiro consolida este modelo de administração de pessoal a administração de recursos humanos deixa de ser uma questāo tāo relcvante. Ao longo do tempo, especialmente no segundo c terceiro períodos (1965-1980 c 1981-1989), o tema recursos humanos perde espaço nos editoriais da Revista, especialmente na reflexão vinculada à 
discussāo da reforma administrativa, para as alieraçōes de estrutura organizacional da administração federal.

\section{Conclusōes}

\section{1}

continuidade da pesquisa através da investigação do contcúdo dos editoriais da Revista reforçou as conclusóes da etapa anterior do trabal ho. Os editoriais da Revista do Serviço Público sofrem, ao longo dos 53 anos da publicação, uma séric de transformaçōes, que acompanham, de forma geral, a mesma lógica de evolução do campo de conhecimento $\mathrm{cm}$ administraçāo pública. Refletem, portanto, a transformação dos estudos sobre - Estado brasilciro, "de uma abordagem técnico-burocrática, para uma tentativa de implantação de políticas públicas, que desemboca, finalmente, na preocupação com o clienteusuário, o cicladão."16

A crescente sofisticação da proxlução em administração pública, identificada anteriormente, encontra eco nos editoriais da Revista, que também se sofisticam, passando a apresentar maior complexidade e profundidade.

Nessa evolução, DASP, Revista do Serviço Público e reforma administrativa caminham sempre juntos. A reforma administrativa tem sempre realçadas as intervençōes em recursos humanos, notadamente nos dois períodos in iciais, onde a Revista possui maior peso no meio político, técnico e acadêmico. O tema reforma administrativa mantém a importância nos editoriais, ao passo que os editoriais sobre recursos humanos, especialmente aqueles de caráter prescritivo, perdem espaço.

Assim como a produção publicada na Revista, analisada no artigo anterior, scus editoriais apresentam como dominante o focus Ciencia Admin istrativa - den tro do movimento de evoluçâo do campo de conhecimento em administração, originado dos primeiros estudos na área pública. O locus hegemôn ico nos editoriais, assim como nos artigos, é listruturação Administrativa do Estado, onde estão contidos os temas estruturadores deste trabalho.

Os editorialistas utilizam abundantemente conceitos e terminologia da ciência da administraçāo para discorrer. predominantemente, sobre temas relativos à estruturação (lo aparato administrativo do Iistado brasilciro. (Os editoriais são formulados como intervençôes em situaçōes de disputa, procurando 
oferecer argumentos científicos às posiçōes defendidas pelos editores da publicação.

No entanto, é perceptivel o enfraquecimento dos editoriais da Revista como instrumento de disputa política. Este fato se relaciona com a perda de importância relativa da Revista c do próprio DASP - que foi responsável pela sua publicação na maior parte do tempo. Com a ampliação do número de atores na administração pública, naturalmente a Revista não manteve sua hegemonia inicial.

Pode-se afirmar, não obstante, que a Revista do Serviço Público utilizou-se dos editoriais para marcar sua influência na gênese do pensamento administrativo brasileiro. Foram um elemento importante para que catalisasse em tomo de si diversas in iciativas de reflexāo sobre a administração pública no Brasil, debatendo idéias fundamentais para a consolidação do novo campo de conhecimento.

\section{Resumen}

LA HISTÓRIA DE LA "REVISTA DO SERVIÇO PÚBLICO" A PARTIR DEL ANALISIS DE SUS EDITORIALES

Evaluación de la trayectoria de la RSP traves del analisis del contenido de sus editoriales en el periodo $1937 \cdot 1989$. El articulo busca complementar el anterior un analisis cantitativo incorporando nuevos elementos de esta vez cualitativos - para analizar el papel de la publicación en la evolución del pensamiento administrativo brasileño. Los temas principales tratados por los editoriales de la Revista y que recibieran mas destaque fueran: la Reforma Administrativa, Recursos Humanos y la própria publicación. Las conclusiones de esta ctapa de la investigación siguen en general las que fueran apresentadas anteriormente, reflejando la transformación de los estudios sobre el Estado Brasileño, de un abordaje técnicoburocrático para una tentativa de implantación de políticas públicas.

\section{Absiract}

THE HISTORY OF THE REVISTA

DO SERVIÇO PUBLICO

THROUGH THE ANALYSIS OF ITS EDITORIALS

The article evaluates the points of view of RSP through the analysis of its editorials writhen from 1937 to 1989. A previous quantitative analysis is now complemented by a qualitative one. It aims to analyse the contribution of the publication for the evolution of brazilian administrative thinking. The main subjects of RSP's editorials, as DASP, Civil Service Reform, Human Resources, are stressed. 
The conclusions go along with the previous analysis, which reflected the changing approach about the brazilian state.

Tania Mezzomo Keinert e José Carlos Vaz sāo pesquisadores da Escola de Administração de Empresas de Sāo Paulo - EAESP/ FGV. 